\title{
Assessing hydrological alterations at multiple temporal scales: Adige River, Italy
}

\author{
G. Zolezzi, ${ }^{1}$ A. Bellin, ${ }^{1}$ M. C. Bruno, ${ }^{2}$ B. Maiolini, ${ }^{2}$ and A. Siviglia ${ }^{1}$ \\ Received 5 July 2008; revised 15 June 2009; accepted 14 August 2009; published 29 December 2009.
}

[1] Hydrological alteration is one of the major threats to the integrity and functioning of riverine ecosystems. We propose to analyze such alterations by means of three approaches: the well-established range of variability approach (RVA), wavelet transform analysis (WT), and a combination of the two. This allows us to separate the most relevant scales of variability and to detect their alteration independently; such information cannot be provided by purely statistical methods like RVA. We show the advantages of this multiple approach through the analysis of two streamflow data sets of the Adige River at Trento, northeastern Italy: a daily streamflow record spanning from 1923 to 2006, and a record of instantaneous measurements with time step of 15 min from 2002 to 2006. Results suggest that starting from the $1960 \mathrm{~s}$, after the construction of the reservoirs currently in operation, a progressive flattening occurred in the hydrograph, which attenuated the amplitude of seasonal variations. This negative tendency worsened in the last few years, possibly as an effect of a reduction in winter snowfall. Wavelet analysis shows that hydroelectric production caused the high-frequency components of the signal to increase in amplitude and number, with fairly regular weekly and daily oscillations and sharp transitions. The whole spectrum of low flows is significantly altered. This alteration of the natural flow has adverse consequences on the ecological integrity of the ecosystem. Use of the range of variability approach, the wavelet transform analysis, and a new methodology which integrates both allows a better separation between natural and human-induced effects at ecologically relevant scales of variability, thereby identifying changes and trends due to hydropower management.

Citation: Zolezzi, G., A. Bellin, M. C. Bruno, B. Maiolini, and A. Siviglia (2009), Assessing hydrological alterations at multiple temporal scales: Adige River, Italy, Water Resour. Res., 45, W12421, doi:10.1029/2008WR007266.

\section{Introduction}

[2] Most river systems across the Alps suffer from streamflow alteration, which induces changes in sediments and organic matter loads, thereby threatening ecosystem integrity. For example, it is now widely recognized that river damming and associated alteration of natural flow, sediment transport, and water temperature, are a cause of degradation of the ecological health of rivers [Karr and Chu, 1999], and decline in freshwater biodiversity [Richter et al., 1998; Revenga et al., 1999; Pringle et al., 2000; Bunn and Arthington, 2002; Nilsson et al., 2005].

[3] Most of the hydrological alterations observed in Alpine rivers and streams are due to hydroelectric power production; for example, in Trentino province, northeastern Italy, about $85 \%$ of water uses are for energy production (Provincia Autonoma di Trento, Piano generale di utilizzazione delle acque pubbliche (PGUAP) relativo alla provincia autonoma di Trento (in Italian), 2006, Trento, Italy). In the 1960s, when the demand for energy showed a burst

\footnotetext{
${ }^{1}$ Department of Civil and Environmental Engineering, University of Trento, Trento, Italy.

${ }^{2}$ Research Innovation Center, IASMA, Edmund Mach Foundation, San Michele all'Adige, Italy.

Copyright 2009 by the American Geophysical Union. 0043-1397/09/2008WR007266\$09.00
}

increase, a large number of reservoirs were built in the Alps to enhance hydropower production in an attempt to meet energy demand, particularly in winter months, when streamflow is low. At that time, more than $80 \%$ of the national energy was produced by hydroelectric. Today, the situation is reversed with hydropower production that decreased to nearly $15 \%$ of the total (Terna S.p.A., Dati storici (in Italian), 2007, available at http://www.terna.it). However, the energy market stimulates hydropower companies to store water at night, when the energy price is low, in order to increase the production at daytime, when the same volume of water produces a much higher revenue. Although a pulsating hydropower production is economically rewarding, it leads to substantial alterations in stream velocity, streambed stability, water temperature and turbidity, and reduces riverine habitat diversity [Cushman, 1985; Allan and Flecker, 1993; McCully, 1996; Maiolini and Bruno, 2008; Richter et al., 1997; Toner and Keddy, 1997; Galat and Lipkin, 2004]. Furthermore, streamflow alterations due to reservoirs operation change over time, according to the evolution of the energy market; the analysis of the alterations is further complicated by constraints on hydropower production resulting from limitations of the water level oscillations in the reservoirs and other water demands, such as, for example, irrigation and artificial snow production. As a consequence of this extreme variability in hydropower production, streamflow is impacted at a broad range of 


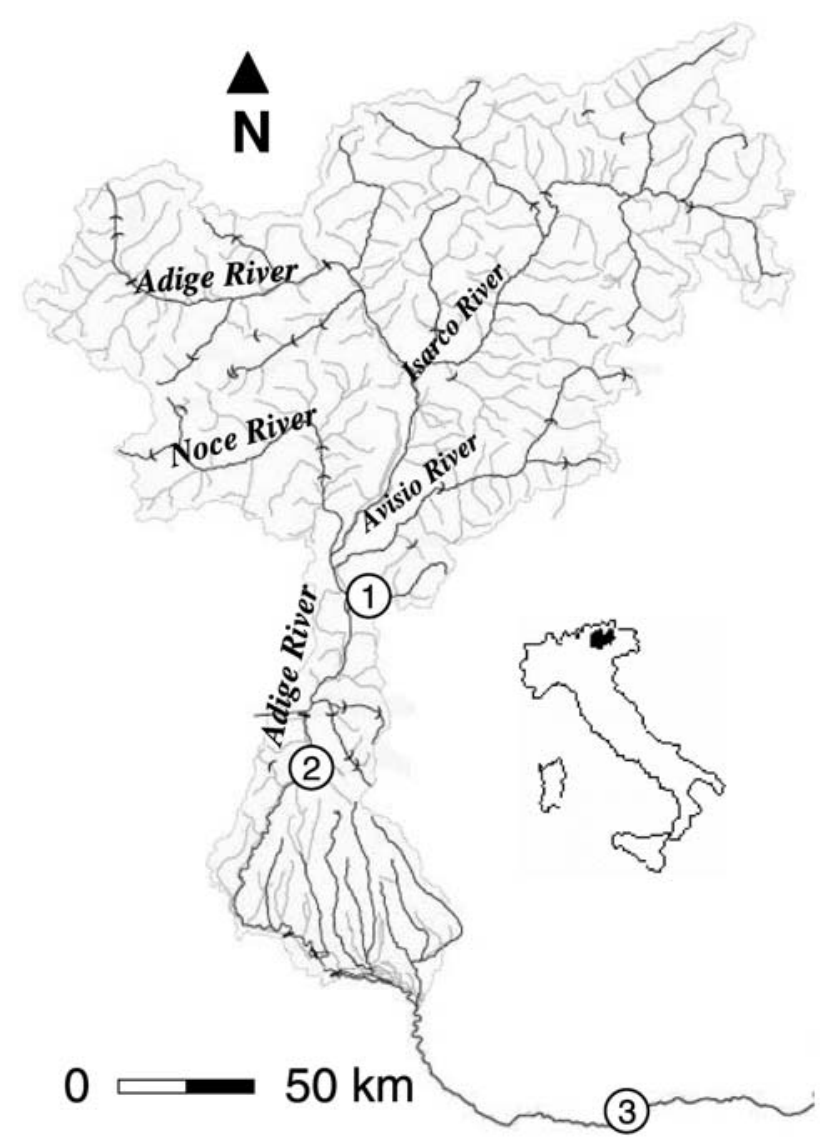

Figure 1. Map of the Adige River watershed, with location of the major dams (indicated by a short arc) and of the gauging stations used for the analysis (1, Trento San Lorenzo (TSL), $46^{\circ} 04^{\prime} 12^{\prime \prime} \mathrm{N}, 11^{\circ} 06^{\prime} 53^{\prime \prime} \mathrm{E} ; 2$, Serravalle, $45^{\circ} 48^{\prime} 31^{\prime \prime} \mathrm{N}$, $11^{\circ} 0^{\prime} 43^{\prime \prime} \mathrm{E}$; 3, Boara Pisani, $45^{\circ} 06^{\prime} 19^{\prime \prime} \mathrm{N}, 11^{\circ} 47^{\prime} 02^{\prime \prime} \mathrm{E}$ ).

scales [Ward et al., 2001], which makes it difficult to identify the most effective remediation strategies.

[4] Hydrological and biogeochemical signals in an unaltered river network result from the combination of hydrological, geochemical and climate processes acting at several time scales. In regulated rivers this variability is altered by water use, thereby it is crucial to separate changes due to climatic forcing from direct anthropogenic effects to better understand how to attenuate the impacts on the ecosystem, and to restore lost ecological functionalities. The characterization of the natural varying flow in a river prior to significant human influence [Botter et al., 2008] provides insight into the flow regime to which native species and ecosystems have adapted [Galat and Lipkin, 2004; Baron et al., 2002; Mathews and Richter, 2007]; this knowledge represents the base for flow ecology models used to provide environmental flow recommendation [Richter et al., 1997; Enders et al., 2009; Richter and Thomas, 2007]. In this context, it has been widely recognized the need of methodologies for assessing flow alterations in riverine systems [Poff et al., 1997].

[5] Five major components of flow regime have repeatedly been considered ecologically important in a broad spectrum of hydroclimatic regions: magnitude, duration, frequency, timing and rate of change; in fact, these flow components provide a heuristic framework for describing the ways in which an organism experiences river flow variability [Mathews and Richter, 2007]. One of the most used approaches to quantify alteration of these components and to set environmental flow targets based upon a river natural flow variability is the range of variability approach (RVA), developed by Richter et al. [1996, 1997, 1998]. According to this approach, anthropogenic alterations of flow are assessed by comparing central tendency and dispersion of 67 hydrologic parameters of ecological relevance that statistically characterize the natural flow regime; these parameters are used to assess and define management targets for the river ecosystem. The advantage of this approach is to combine ecological significance with streamflow characteristics, thus providing operational applicability. However, the method does not characterize the complex temporal patterns typical of lotic ecosystems [Ward, 1989], and most importantly, does not identify the impacted time scales in altered rivers, which is a crucial information for defining the remediation actions. An ideal tool for this purpose is the wavelet transform (WT) [e.g., Morlet, 1983], which has been extensively used in climatology [Torrence and Compo, 1998], and is increasingly applied in freshwater ecology [Steel and Lange, 2007] and in different areas of hydrology [Foufoula-Georgiou and Kumar, 1995; Nakken, 1999], in particular to detect spatial and temporal patterns of rainfall [Kumar and FoufoulaGeorgiou, 1993; Kwon et al., 2007], surface heat fluxes [Katul and Parlange, 1995; Katul et al., 1998], streamflow [Saco and Kumar, 2000], river networks [Lashermes and Foufoula-Georgiou, 2007] as well as heterogeneous porous media [Qi and Neupauer, 2008].

[6] In this paper we investigate the alteration of the natural flow regime of the Adige River due to hydropower production from the analysis of two streamflow data sets collected at the gauging station of Ponte San Lorenzo in the city of Trento, which is located in the middle course, after the river receives water from the major tributaries (Figure 1). After applying the RVA method and the wavelet transform separately, we combine the strength of the two methodologies in a new approach, to better quantify the impact of hydropower operations on streamflow at the scales of variability which are most relevant for the ecosystem, such as annual, seasonal and weekly time scales.

\section{Data and Methods}

\subsection{Adige River System}

[7] The Adige River originates in the northwestern part of the Trentino Alto Adige region, northeastern Italy, and flows to the southeast to enter the Adriatic Sea south of Venice. The main stream is $409 \mathrm{~km}$ long and it drains a catchment of $12,100 \mathrm{~km}^{2}$ entirely located on the southern part of the Alps. Streamflow data were recorded at the historical stream gauge of Ponte San Lorenzo which is located in the city of Trento, $156 \mathrm{~km}$ from the river's spring, at the elevation of $186 \mathrm{~m}$ a.s.1. $\left(46^{\circ} 04^{\prime} 07^{\prime \prime} \mathrm{N}, 11^{\circ} 06^{\prime} 53^{\prime \prime} \mathrm{E}\right)$, where the contributing watershed area is $9763 \mathrm{~km}^{2}$, i.e., $88.7 \%$ of the total drainage area (Figure 1). Headwaters are located in the central part of the Alps, which are character- 


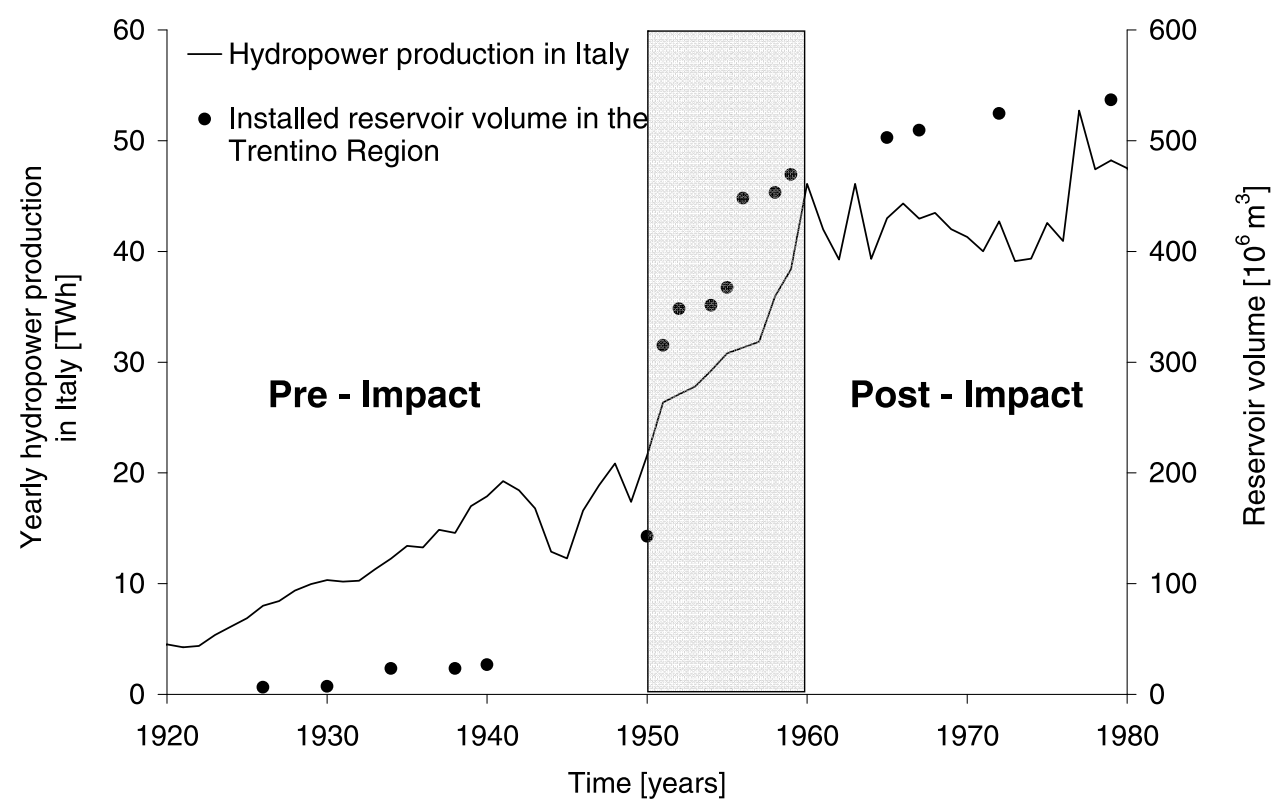

Figure 2. Historical development, from 1920 to 1980, of cumulative reservoir volume in the Adige River basin (solid circles and right axis) and gross national hydropower production in Italy (solid line and left axis).

ized by a typical mountain climate with winter drought, late spring snowmelt and humid summers and falls. The upper part of the catchment hosts 185 glaciers covering a total surface of about $200 \mathrm{~km}^{2}$. Because of its morphology and humid climate, the catchment is well suited for hydroelectric production, and to date 30 major reservoirs (i.e., reservoirs with a total volume larger than $10^{6} \mathrm{~m}^{3}$ or created by a dam higher than $30 \mathrm{~m}$ ) exist in the catchment, for a total storage capacity of $571 \times 10^{6} \mathrm{~m}^{3}$, corresponding to $8.5 \%$ of the long-term mean annual runoff. These reservoirs supply 34 major hydropower plants, for a total installed power of $983 \mathrm{MW}$, and potential energy production of $4123 \mathrm{GWh} /$ year. In addition, 27 smaller power stations with small or no impoundment have an installed power between 1000 and $3000 \mathrm{~kW}$ each. An amount as large as $85 \%$ of the actual total storage capacity was built in the period 19501960 , while of the remaining $15 \%$, only $5 \%$ was present before 1940 and $10 \%$ was built after 1960 . As expected, this trend parallels the increase of the gross national hydropower production, as shown in Figure 2. According to the temporal changes of the impoundment volume shown in Figure 2, we considered the period before 1950 as the preimpact period and the period after 1960 as the postimpact period.

\subsection{Streamflow Data}

[8] The daily streamflows recorded from 1 January 1923 to 31 December 2006 at Trento Ponte San Lorenzo gauging station (TSL) were selected for the analysis. Daily streamflows at TSL were recorded by the Magistrato alle Acque di Venezia (Water Magistrate of Venice) from 1923 to 1975, and in the following years by the Ufficio Idrografico della Provincia Autonoma di Trento (Hydrograph Service of the Autonomous Province of Trento) first, and then from 1987 by the Servizio Opere Idrauliche della Provincia Autonoma di Trento (SOI) (Service for Hydraulic Works of the Autonomous Province of Trento). Instantaneous streamflow data recorded at $15^{\prime}$ sampling intervals, for the period 2002-2006, were provided by SOI as well.
[9] The time series of daily streamflow data shows a gap between 1944 and 1950. In order to fill this gap we used streamflow data recorded at Serravalle gauging station, $35 \mathrm{~km}$ downstream of Trento and with a contributing area of $10,514 \mathrm{~km}^{2}$ only $8 \%$ larger than the contributing area at TSL. Data for the water year 1944 were missing from Serravalle as well, and were reconstructed through a linear regression between measured streamflow in the period $1923-1943$ at TSL and at a second gauging station, Boara Pisani (BP), located $102 \mathrm{~km}$ downstream of TSL, with a contributing area of $11,954 \mathrm{~km}^{2}$ (Figure 1). The linear regression between streamflow at TSL and BP resulted in the following relationship with correlation $\rho=0.915$ :

$$
Q_{T S L}=1.015 Q_{B P}-38.651
$$

where $Q_{T S L}\left[\mathrm{~m}^{3} / \mathrm{s}\right]$, and $Q_{B P}\left[\mathrm{~m}^{3} / \mathrm{s}\right]$ are the streamflow at TSL and BP, respectively. The normalized daily streamflow fluctuations at TSL is defined as

$$
q_{j}=\frac{Q_{T S L, j}-\bar{Q}_{T S L}}{\sigma_{Q}} \quad, \quad j=1, \ldots N
$$

where $Q_{T S L, j}$ is the daily streamflow at the day $j$ since the beginning of the time series,

$\bar{Q}_{T S L}=\sum_{j=1}^{N} Q_{T S L, j} / N \quad$ and $\quad \sigma_{Q}=\sqrt{\frac{\sum_{j=1}^{N}\left(Q_{T S L, j}-\bar{Q}_{T S L}\right)^{2}}{N-1}}$

are the mean and the standard deviation, respectively, and $N=30,681$ is the dimension of the sample. The normalized daily streamflow fluctuations at TSL are shown in Figure $3 a$.

\subsection{Methods of Data Analysis}

[10] We applied both the RVA and the WT methods to the daily streamflow data described in section 2.2 , and only the 

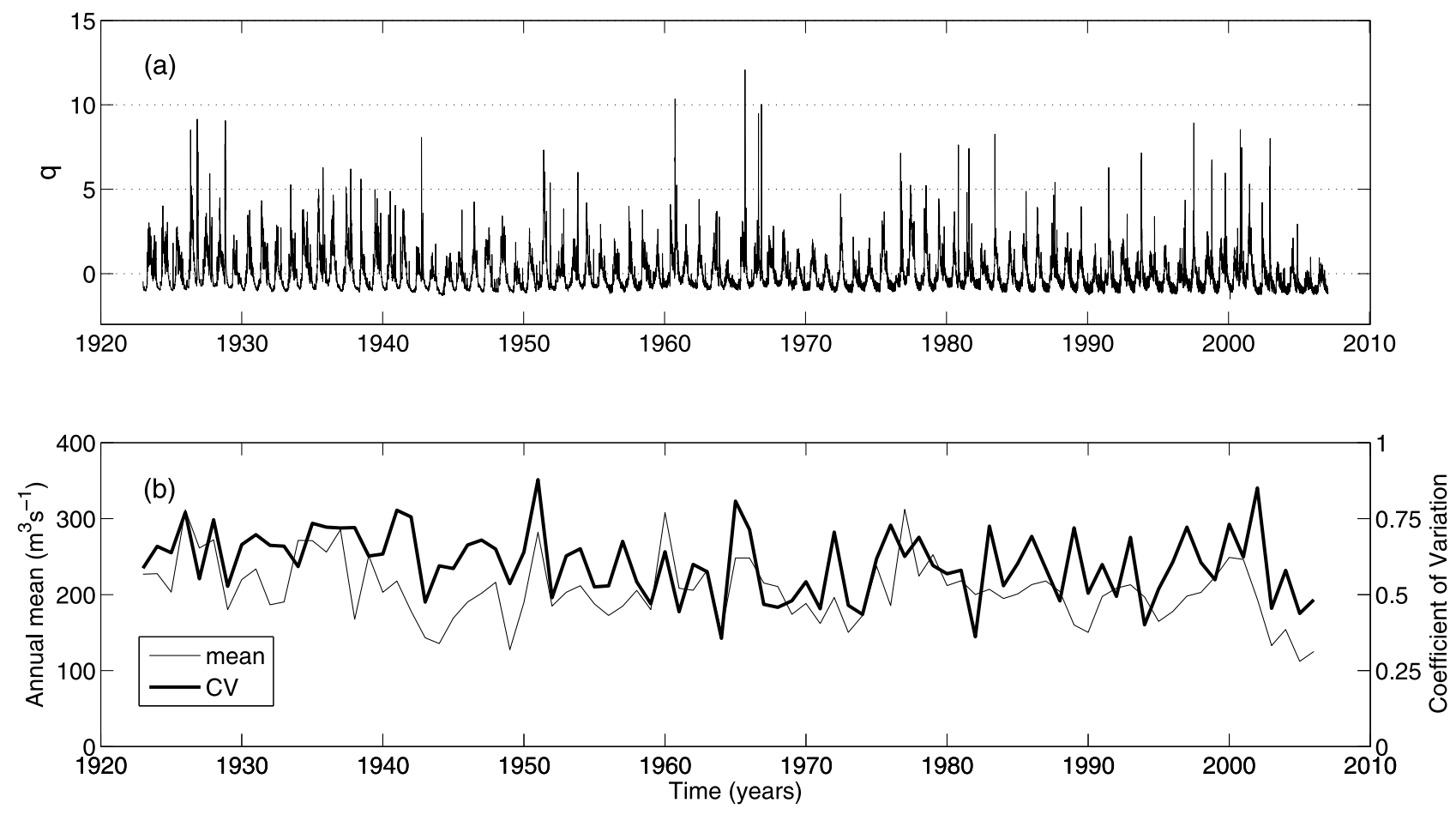

Figure 3. (a) Normalized daily streamflow at TSL from 1923 to 2006. (b) Annual mean and coefficient of variation of the daily streamflow.

WT method to the $15^{\prime}$ data, because the RVA approach has been designed for application to daily data. The main features of the two approaches which are relevant for the present analysis are summarized below. Given that periods of attenuated streamflow variability result in smaller fluctuations around the mean, a first indicator of a modified intra-annual variability is the coefficient of variation. Figure $3 \mathrm{~b}$ shows both the annual mean and the coefficient of variation of the daily streamflow from 1923 to 2006 . While a significant reduction of the annual mean streamflow is observed in the last 6 years of the time series, no significant differences are observed in the coefficient of variation of the preimpact and postimpact periods. This shows that the simple analysis of the coefficient of variation does not allow to identify streamflow alterations.

\subsubsection{Range of Variability Approach (RVA)}

[11] The RVA method analyzes the interannual variability of a series of streamflow parameters which reflect the following five fundamental attributes of river flow with ecological significance: magnitude, timing, frequency, duration and rate of change of water discharge [Richter et al., 1996, 1997, 1998; Poff et al., 1997; Scott et al., 1997].

[12] RVA is based on the concept that postregulation river flows should be managed in such a way to mimic the variability that these parameters showed in the preimpact period, for example, by imposing that the probability of occurrence of streamflow values within selected ranges is the same in the preimpact as in the postimpact periods [Richter et al., 1997]. In the absence of specific ecological information, these ranges are identified by using percentiles as separators between different classes. In this study we adopt the nonparametric approach, which uses the median (50th percentile) as central tendency value and the range between the 34th and the 67th percentile as targeted range of variability for the postimpact period.
[13] RVA is applied by using the free software IHA7 (Indicators of Hydrological Alteration version 7.0.0 Beta 4.10, (C) The Nature Conservancy, 1996-2005), which computes a total of 67 streamflow parameters grouped into 33 IHA parameters and 34 environmental flow components (EFC) parameters.

[14] IHA parameters are biologically relevant streamflow statistics that characterize intra-annual variations (for example, the median streamflow of each calendar month, and the magnitude, timing and frequency of annual minima and maxima) and are analyzed to quantify the interannual variation of the flow regime [Richter et al., 1996]. EFC parameters result from partitioning the river hydrograph into a set of hydrographic patterns with ecological relevance [e.g., Mathews and Richter, 2007]. The basic partition is between low and high flows, with the former being higher than the 75th percentile, and the latter smaller than the 50 th percentile. A set of rules is further prescribed to choose between low- or high-flow categories when the streamflow ranges between the 50th and the 75th percentile. Low-flow events are further classified as either low flows or extreme low flows, the latter occurring when the streamflow is lower than the 10th percentile of all low flows. High-flow events are divided into high-flow pulses, small floods, and large floods according to their return period (at least 2 years for small and at least 10 years for large floods).

[15] As a first step of the procedure, IHA7 computes the statistics of the above 67 parameters with reference to the preimpact or reference period. The alteration is then assessed by assigning to each parameter an hydrologic alteration (HA) index, which is computed through the following steps: (1) three categories are defined using the 34th and the 67th percentiles as separators: the lower category includes values from 0 to 33th percentile, the middle category from 34 th to the 67 th percentile and the 
upper category from the 68th percentile upward; (2) for a given parameter, the frequency with which it belongs to each one of the three categories is computed separately for preimpact and postimpact periods (3) the HA index is then computed for each category as the relative difference between the frequency in the postimpact and preimpact periods. The resulting HA index can assume values in the range $[-1, \infty)$, with positive values indicating that the postimpact time series shows a higher frequency of occurrence of values belonging to the selected category. Each parameter is therefore characterized by three HA values, one for each category.

\subsubsection{Wavelet Transform}

[16] In essence, wavelets transform can be seen as a mathematical tool for extracting the dominant modes of variability from statistically non stationary signals. In fact, WT is localized in time, and thus makes possible to detect time variations in the modes of variability associated to signal unsteadiness [see, e.g., Daubechies, 1992; Lau and Weng, 1995; Torrence and Compo, 1998]. This is accomplished by letting the width of the wavelet to increase with the period, thus allowing a more efficient and accurate localization of changes in the dominant modes of variability with respect to the windowed Fourier transform (WFT), which uses a fixed-width window [Kaiser, 1994; Lau and Weng, 1995]. For this reason, wavelets decomposition has been extensively used in geophysical studies [FoufoulaGeorgiou and Kumar, 1995].

[17] The continuous wavelet transform $W_{n}(s)$ of a discrete sequence $x_{n}, n=1,2, \ldots N$, where $N$ is the length of the series, is defined as follows [Torrence and Compo, 1998]:

$$
W_{n}(s)=\sum_{n=0}^{N-1} x_{n^{\prime}} \Psi^{*}\left[\frac{\left(n^{\prime}-n\right) \Delta t}{s}\right]
$$

where $\Delta t$ is the sampling time step, $\eta=\left(n^{\prime}-n\right) \Delta t$ is the dimensionless time and superscript $*$ indicates the complex conjugate.

[18] The wavelet function $\Psi(\eta)=(2 \pi s / \Delta t)^{1 / 2} \psi_{0}(\eta)$ is obtained by normalizing a "mother" wavelet $\psi_{0}(\eta)$ such as to respect the following condition:

$$
\sum_{k=0}^{N-1}\left|\Psi\left(s \omega_{k}\right)\right|^{2}=N
$$

at each scale $s$. In equation (4) $\omega_{k}=2 \pi k / N \Delta t$, for $k \leq N / 2$, and $\omega_{k}=-2 \pi k / N \Delta t$, otherwise. In addition, the mother wavelet should have unit energy, i.e., $\int_{-\infty}^{\infty}\left|\psi_{0}\left(\omega^{\prime}\right)\right| d \omega^{\prime}=1$. In this paper we utilize the Morlet and the Paul functions as mother wavelets because they have been shown suitable to detect oscillating patterns [Torrence and Compo, 1998]. They read

$$
\begin{gathered}
\psi_{0}(\eta)=\pi^{-1 / 4} e^{i \omega_{0} \eta} e^{-\eta^{2} / 2} \quad(\text { Morlet }) \\
\psi_{0}(\eta)=\frac{2^{m} i^{m} m !}{\sqrt{\pi(2 m) !}}(1-i \eta)^{-(m+1)} \quad(\text { Paul })
\end{gathered}
$$

where we assume $\omega_{0}=6$ and $m=6$ for the Morlet and for the Paul wavelet, respectively.
[19] The wavelet transform (3) is typically computed at the following set of scales:

$$
s_{j}=s_{0} 2^{j \Delta j} \quad(j=1,2, \ldots, J),
$$

where $s_{0}$ is the smallest scale considered in the analysis and $J=\Delta j^{-1} \log _{2}\left(N \Delta t / s_{0}\right)$, such that the largest scale is $N \Delta t$, i.e., the length of the time series. Furthermore, $\Delta j$ is the inverse of the number of scales per each octave, and $s_{0}$ should be chosen such as to obtain a minimum Fourier period of $2 \Delta t$. Because the equivalent Fourier period for the Morlet wavelet is given by $\lambda_{j}=1.03 s_{j}$, in all computations we have chosen to use $s_{0}=2 \Delta t$, and $\Delta j=1 / 12$ such as to obtain a smooth wavelet spectrum.

[20] The distribution of energy among the modes of variability (periods) is described by the wavelet power spectrum (WPS) which is given by: $W_{n}^{2}(s)=\left|W_{n}(s)\right|^{2}=$ $W_{n}(s) W_{n}^{*}(s)$. Interesting pieces of information on the nature of the signal can be obtained by analyzing how signal energy, which is proportional to the amplitude of the fluctuations, varies with time. This can be obtained by computing the scale-averaged wavelet power spectrum (SAWPS) between the two scales of interest, $s_{1}=s_{0} 2^{l_{1} \Delta_{j}}$ and $s_{2}=s_{0} 2^{l_{2} \Delta_{j}}$, as follows:

$$
{\overline{W_{n}}}^{2}=\frac{\Delta j \Delta t}{C_{\delta}} \sum_{j=l_{1}}^{l_{2}} \frac{\left|W_{n}\left(s_{j}\right)\right|^{2}}{s_{j}}
$$

where $C_{\delta}$ is a reconstruction factor, which for the Morlet wavelet with $\omega_{0}=6$ assumes the value 0.776 . In addition, the time average of the WPS from $t_{1}=n_{1} \Delta t$ to $t_{2}=n_{2} \Delta t$ retains the most significant features of the time interval $\left[t_{1}, t_{2}\right]$

$$
{\overline{W_{p}}}^{2}(s)=\frac{1}{\Delta n} \sum_{n=n_{1}}^{n_{2}}\left|W_{n}(s)\right|^{2}
$$

where $\Delta n=n_{2}-n_{1}$ and $p$ is a suffix that identifies the time interval over which the average is computed. The resulting local wavelet power spectrum (LWPS) can be used to detect changes in the characteristics of the time series between two observation periods, such as those separated by the construction of most of the water reservoirs that affect streamflow.

\section{Streamflow Analysis}

[21] The daily streamflow of four typical years, two (1923 and 1930) in the preimpact and two (1998 and 2003) in the postimpact periods at TSL are shown in Figures $4 \mathrm{a}-4 \mathrm{~d}$. These hydrographs provide a description of the hydrological regime of the Adige River and show qualitatively several features that will be quantified in more detail through the analysis with RVA and wavelet transform. Preimpact years are characterized by early summer high flows which are typically followed by a recession period in the late summer and fall, sometimes interrupted by a sudden increase of streamflow triggered by intense storms associated to cyclonic events. What is most evident in the 2 years of the postimpact period is a strong reduction of the early summer high flows. Overall, early summer flow tends to be lower in the postimpact periods, although large variations 
(a) 1928

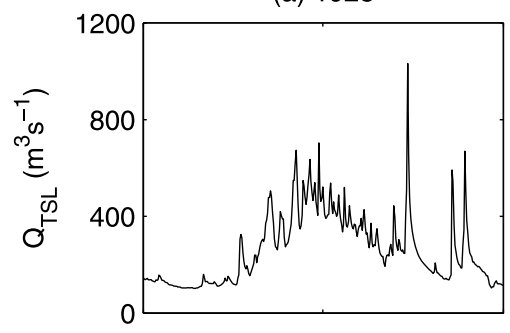

(c) 1998

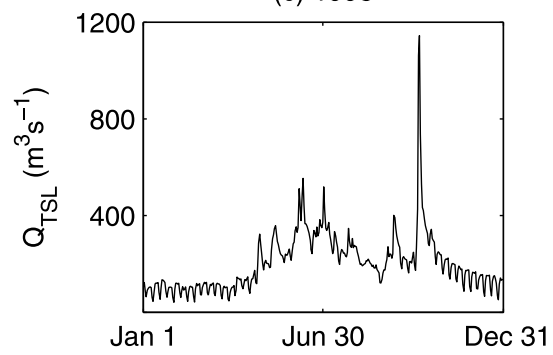

(b) 1930

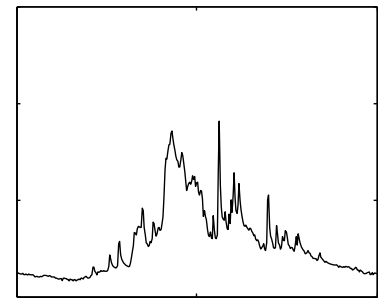

(d) 2003

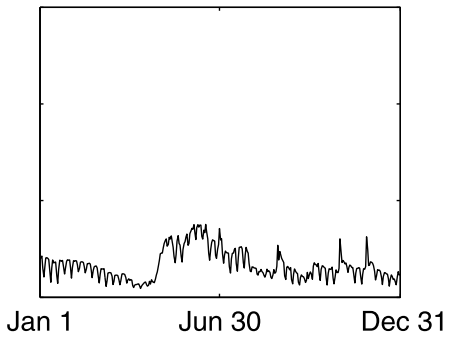

Figure 4. Yearly hydrographs at TSL for $(a, b) 2$ sample years in the preimpact and (c, d) 2 sample years in the postimpact period.
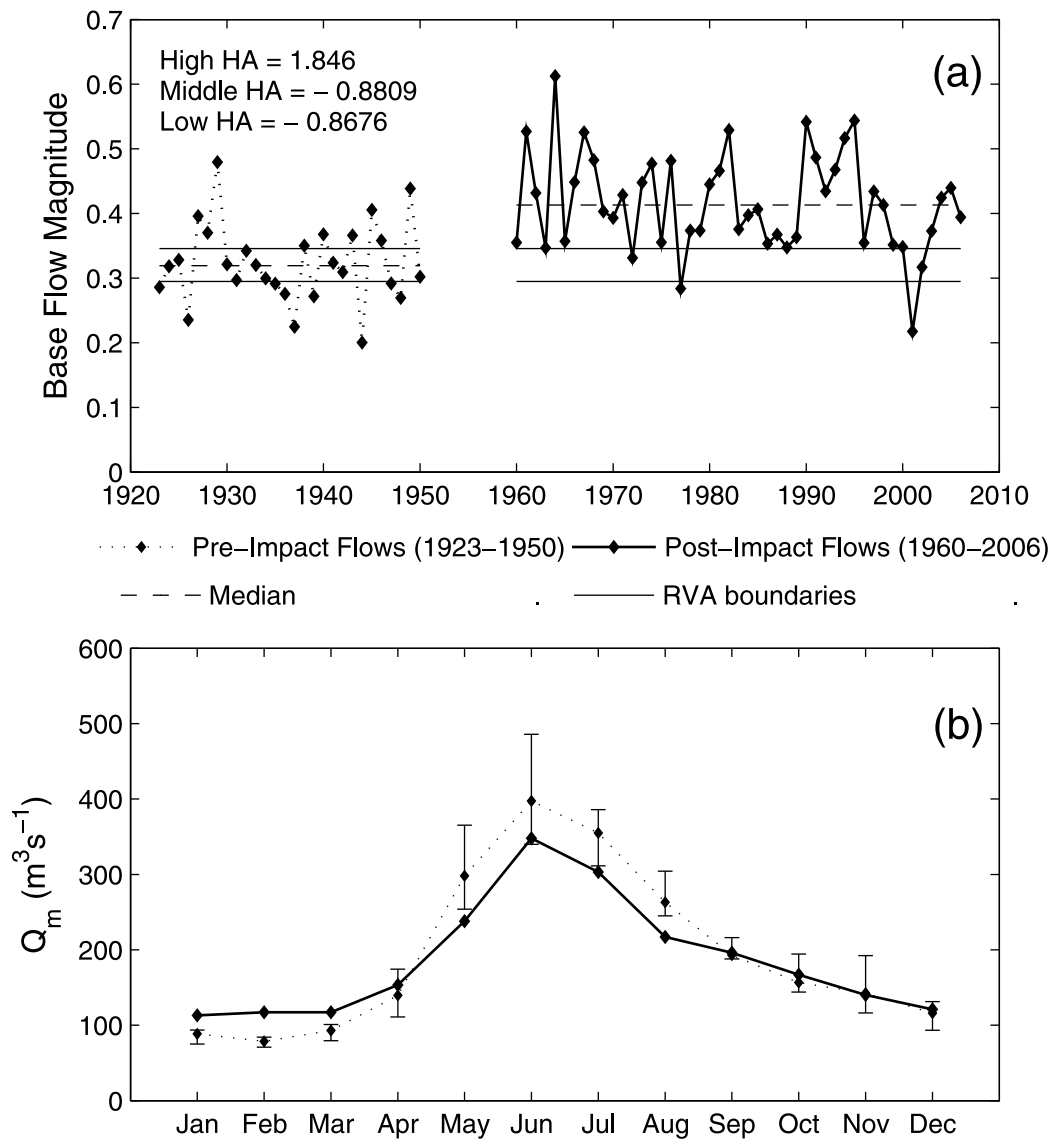

Figure 5. Results of RVA analysis. (a) Base flow index and the corresponding HA factor for high, middle, and low RVA categories. Solid lines indicate the limits of the middle category, while dashed lines indicate the median of the preimpact and postimpact periods. (b) Median of the monthly average flows for the preimpact and postimpact periods. 

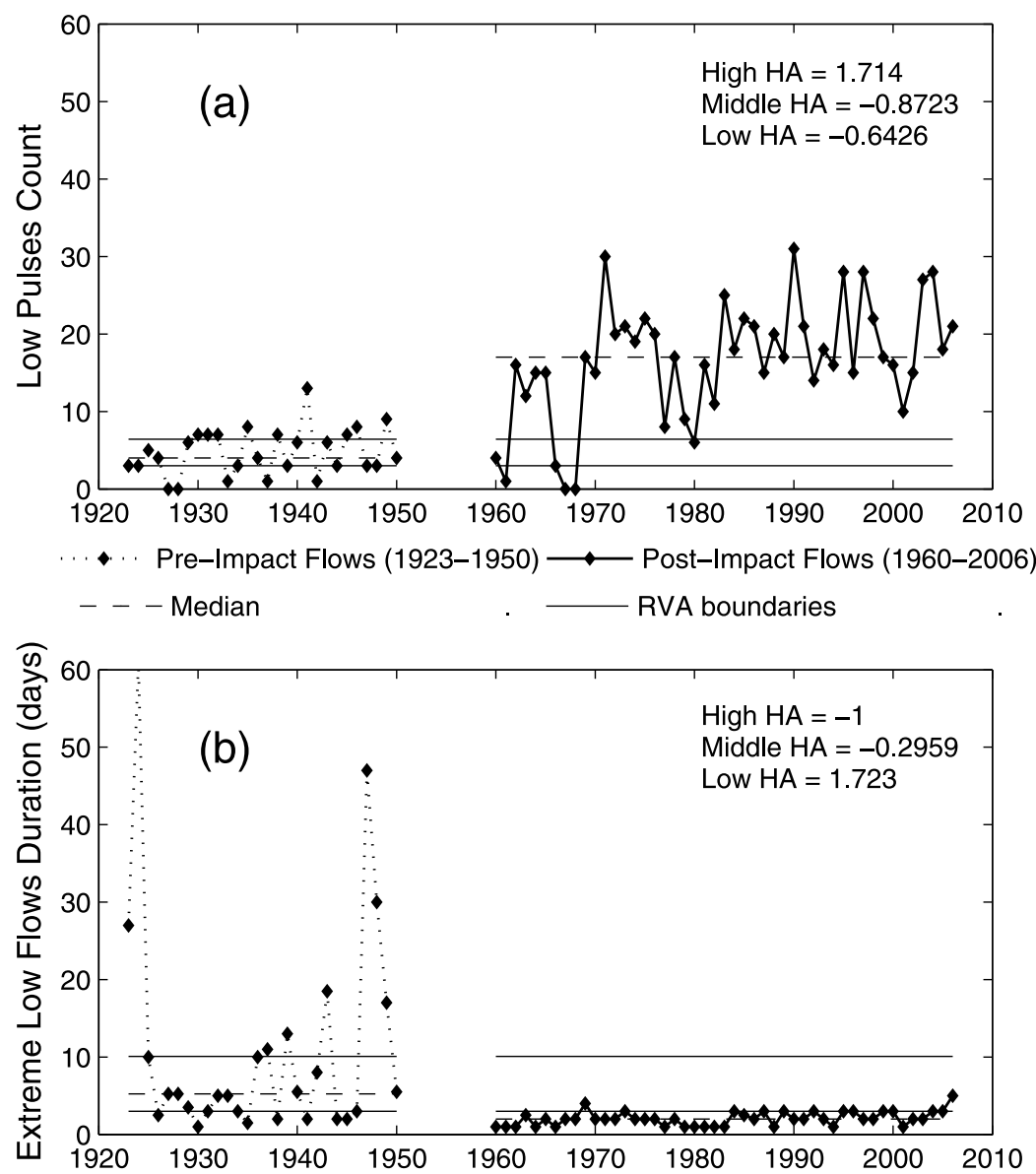

Figure 6. Results of RVA analysis. (a) Number of low pulses and (b) median duration of extreme low flows in each year for preimpact and postimpact periods at TSL and corresponding hydrological alteration factor HA for high, middle, and low RVA categories. Solid lines indicate the limits of the middle category, while dashed lines indicate the median of the preimpact and postimpact periods.

are observed from year to year. In addition, the postimpact years are characterized by short-period oscillations, which are particularly evident in the low-flow season, which were absent in the preimpact years. These oscillations, with temporal scale of about 7 days, are due to hydropower production which is higher from Monday to Friday and is reduced, if not eliminated, during the weekend.

\subsection{Range of Variability Approach}

[22] We analyze the parameters that showed the most significant alteration among the 67 parameters of RVA: the base flow index, the median of the monthly average flows, the number of low and high pulses, the duration of the extreme low flows, and finally, the rise and fall rates. These parameters are commented in detail below.

[23] The base flow index is defined as the ratio between the annual minimum of the 7 day moving average and the annual mean streamflow. Figure 5a shows the time series of the base flow index in the preimpact and postimpact periods together with the median value (dashed line) and the boundaries of the middle category (i.e., from 34th to 67 th percentile), which is computed with reference to the preimpact period. The base flow index is larger in the postimpact period as an effect of the water released from the reservoirs in winter for hydropower production when natural flow is at its minimum. This is shown by a higher persistence of annual base flow index in the upper category (i.e., $\mathrm{HA}=1.85$ for the upper category, which contains the median) and a correspondingly lower persistence in the middle and lower categories, as shown by the negative HA indexes of -0.88 and -0.87 , respectively. Figure $5 b$ shows how the median of the monthly average flows changes from the preimpact to the postimpact period. In the postimpact period the median is lower from April to September, substantially unaltered between September and December and higher from January to March. This confirms what evidenced by the base flow index, i.e., that in the postimpact period water volumes are stored in the reservoirs in summer to be released in winter. This is not surprising, since the reservoirs had been built for this purpose; however, as will be shown later by wavelet transform, this is only the average trend, and significant changes occurred in the way reservoirs were managed from the early 1960s to the last few years with a more variable energy market.

[24] Figure 6a shows the number of low pulses occurring within a year in both the preimpact and postimpact periods. A low pulse is identified and counted when the streamflow falls below the 25 th percentile of the preimpact period for a limited amount of time. In a typical year low pulses occurred approximately four times more often in the postimpact period with a strong increase of their number in the upper category $(\mathrm{HA}=1.714$, Figure 6a). Moreover, the 

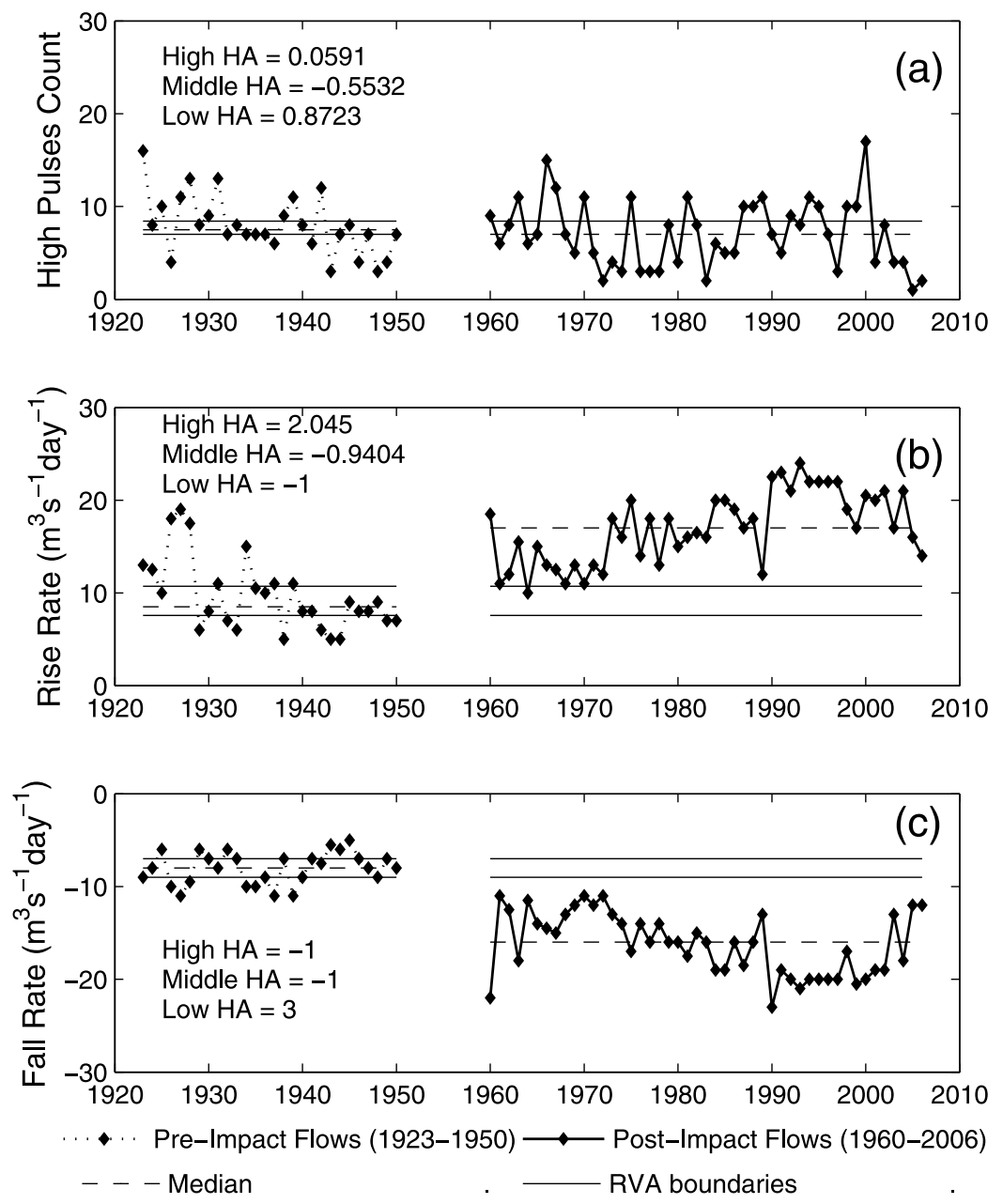

Figure 7. Results of RVA analysis. (a) Number of high pulses, (b) rise rate, and (c) fall rate for preimpact and postimpact periods at TSL and corresponding hydrological alteration factor HA for high, middle, and low RVA categories. Solid lines indicate the limits of the middle category, while dashed lines indicate the median of the preimpact and postimpact periods. Note that the value of the postimpact median of the high pulse count (Figure 7a) is nearly coincident with the low RVA boundary, so the two lines overlap.

duration of the extreme low flows has been much shorter $(\mathrm{HA}=1.723$ in the lower category) with almost no interannual variability (Figure 6b), a change which results in values below the RVA target. In fact, while the extreme low flows could last up to several weeks in the preimpact period, their duration never exceeded 5 days after 1960. In that period, both low flows and low pulses occurred mostly during the weekends, when hydropower production was absent, or strongly reduced because of the lower-energy request. In this situation, reservoirs store water and therefore only a fraction of the catchment contributes to streamflow at TSL. Figure 7a repeats Figure 6a for the number of high pulses occurring within a year. The number of high pulses were less affected than the low pulses, although in the postimpact period they tended to be less frequent ( $\mathrm{HA}=$ 0.8723 for the number of high pulses in the lower category) than in the preimpact period, with higher interannual variability. Furthermore, although of slightly longer duration, they were almost always outside the RVA target (highflow duration $\mathrm{HA}=0.2577$ in the upper category), probably because of the effect of reservoirs, which act mitigating the extremes, i.e., reducing high flows and increasing low flows.

[25] Changes of streamflow in the postimpact period tended to be more abrupt and frequent than in the preimpact period: the rise rate, quantified as the median of all positive differences between consecutive daily values (computed separately for each year), showed a strong increase (HA = 2.045 in the upper category), and always fell well above the target values (Figure 7b), whereas the fall rate (i.e., the median of all negative differences between consecutive daily values), decreased ( $\mathrm{HA}=-0.9338$ in the lower category), always falling well below the target values (Figure 7c).

\subsection{Wavelet Analysis of Daily Streamflow for the Whole Period, 1923-2006}

[26] The normalized streamflow at TSL (Figure 3a) is transformed by using the Morlet WT, and the resulting wavelet power spectrum is shown in Figure 8. We repeated the computation by using the Paul mother wavelet with $m=6$ obtaining similar results. 


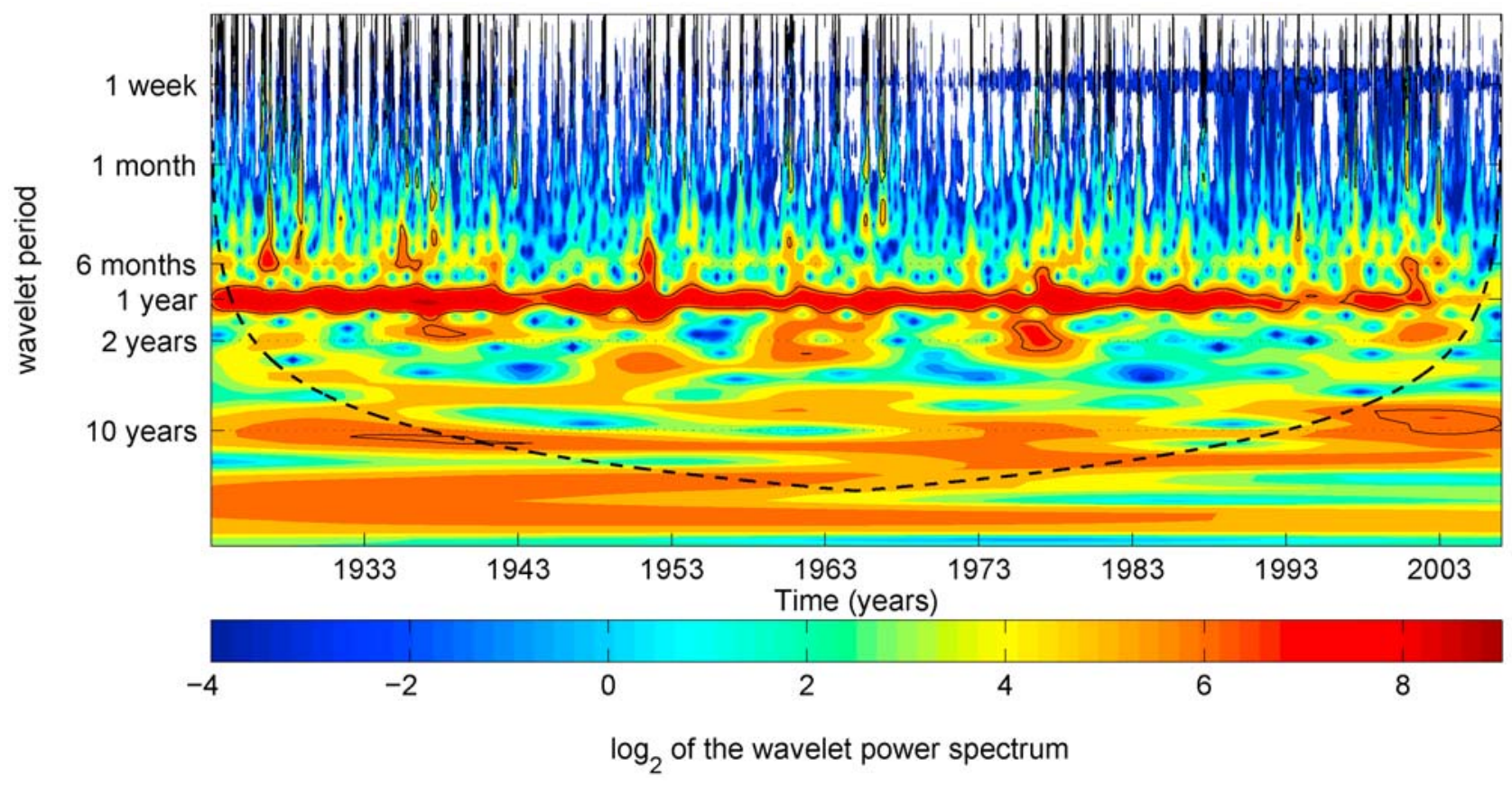

Figure 8. Wavelet power spectrum (WPS) of the daily streamflow at TSL (1923-2006). The plot has a color scale ranging from blue (low energy) to red (high energy).

[27] As expected periods ranging from 256 to 512 days are characterized by high-energy content. This is due to the control that alpine climate exerts on the streamflow signal, which alternates low flow conditions in winter, when precipitations are mostly solid, to high-flow conditions in early summer, when snowmelt occurs. Notice that the energy associated to these modes of variability attenuates after 1993. The analysis of the daily time series revealed in fact that starting from 1993 only the years 1997 and 2001 showed a total runoff from June to July larger than the mean of the period 1923-2006, with relative differences of $12 \%$ and $24 \%$, respectively. In all the remaining years, runoff was instead significantly lower than the mean with relative differences with respect to the mean ranging from $-4 \%$ in 1999 to $-57 \%$ in 2005 . Furthermore, in the last 5 years of the time series, i.e., from 2002 to 2006, the summer runoff was always lower than the mean with relative differences ranging from $-23 \%$ to $-57 \%$. This is in line with the flattening of the WPS in the last 4 years of the time series, as shown by the red color turning to orange and yellow in Figure 8. On the contrary, the winter runoff from December to February preserved the type of variability observed

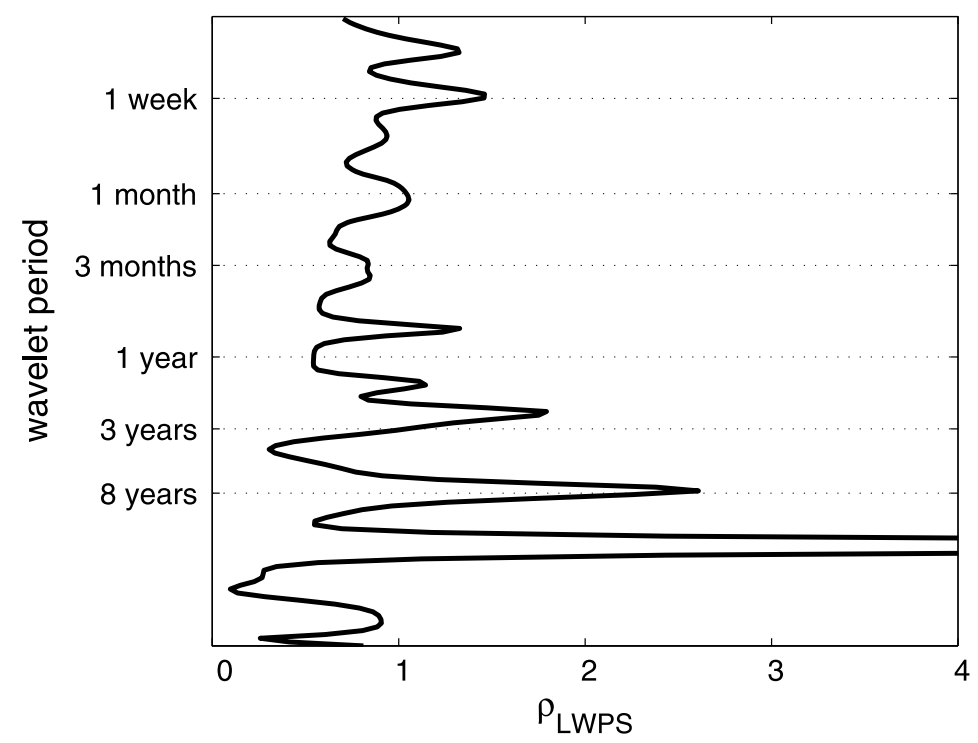

Figure 9. Ratio $\rho_{L W P S}$ between the local WPSs of the postimpact $(1960-2006)$ and the preimpact period $(1923-1950)$. 


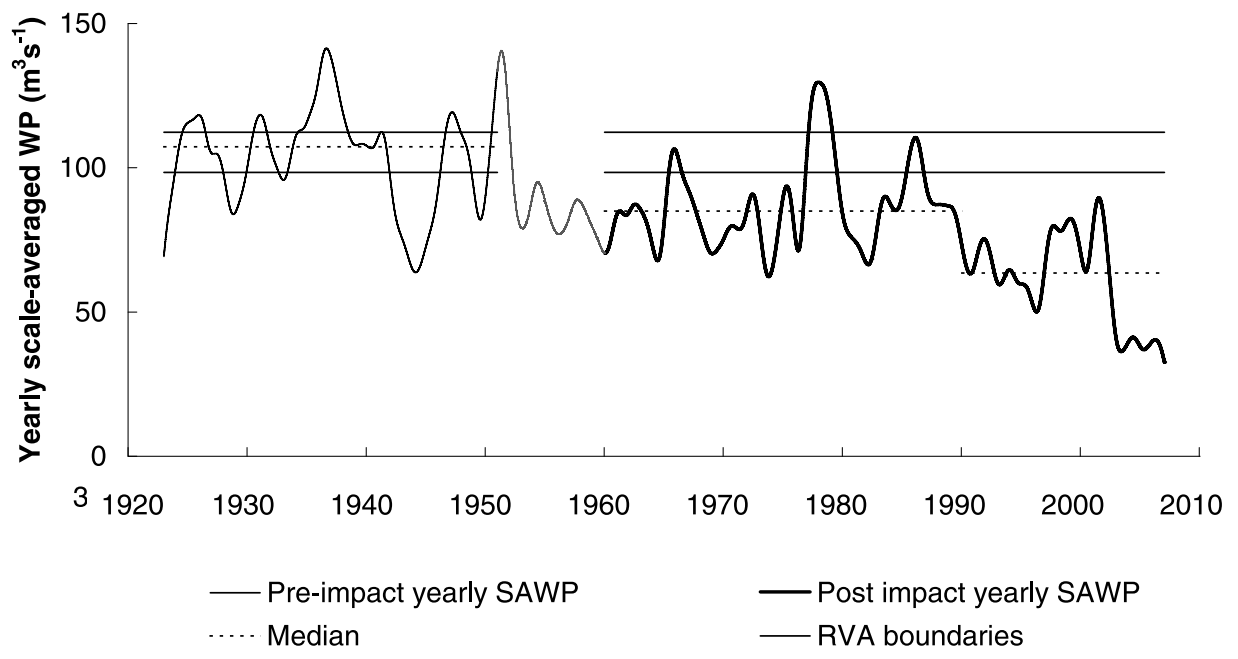

Figure 10. Application of the RVA to the scale-averaged WPS for scales ranging from 256 to 512 days (yearly scale). Solid lines indicate the limits of the middle category, while dashed lines indicate the median of the preimpact and postimpact periods.

before 1993, with the exception of the last three winters (i.e., 2003-2005), in which the runoff was lower than the mean by $23 \%, 13 \%$ and $34 \%$, respectively.

[28] The modification of the WPS in the postimpact period is analyzed with more details in Figure 9, which shows the ratio $\rho_{L W P S}$ between the Local WPSs of the postimpact and preimpact periods extracted from Figure 8. Note that periods with $\rho_{L W P S}>1$ are characterized by a higher energy in the postimpact than in the preimpact period, while the contrary is observed for $\rho_{L W P S}<1$. The attenuation of oscillations of periods in the range between 256 and 512 days, already observed in Figure 8, is here confirmed by values of $\rho_{L W P S}<1$, which within the smaller range between 333 and 420 days assumes the nearly constant value of 0.5 , thereby showing that the interannual variability of streamflow in the postimpact period has been in average reduced by $50 \%$, but with a even stronger reduction in the last 4 years of the time series. Periods of about 2 months (62 days) and 18 days are also attenuated even if to a lesser extent than the annual oscillations. In addition, the postimpact local WPS is attenuated over the broad range of periods, ranging from 8 to 222 days, with the exception of a very narrow band around 32 days where $\rho_{\text {LWPS }}$ is slightly larger than one.

[29] The higher amplitude of oscillations with periods centered in a narrow band around 7 days in the postimpact years can be attributed to hydropower production, whose effect is to increase streamflow from Monday to Friday and reduce it during the weekend. In fact, the WPS shown in Figure 8 clearly indicates that streamflow has been altered at this scale only after the period of major reservoir construction (1950-1960). Note that the distance between the blue spots at the top right of Figure 8 gradually decreases with time from 1960 until approximately 1980, when they merge into a nearly uniform blue band, which indicates strong regularity of the weekly streamflow oscillations. Such regularity attenuates in the latest years.

[30] More quantitative considerations will be formulated in section 3.3 when the WPS averaged at this band of scales (4-8 days) will be analyzed through the IHA software. Moreover, the recent evolution of this part of the spectrum will be studied subsequently by using data with $15^{\prime}$ time interval for the years from 2000 to 2006 . The two peaks at periods of 236 and 839 days, (i.e., slightly less than 8 months and 2 years and 9 months, respectively) cannot be directly related to changes in river regulation occurring after 1960, and are not commented on here.

\subsection{Options to Integrate the RVA and Wavelet Transform}

[31] In section 3.2 we showed that important components of natural variability in streamflow, such as variations at the scales of 1 year or 6 months, are attenuated in the postimpact period. However, this attenuation changes over time as a consequence of several factors, including changes in hydropower production and possibly climate change. For example, the attenuation of oscillations with periods between $s_{1}=256$ and $s_{2}=512$ days is much stronger in 2000-2006 than before. This variability in the attenuation is not evidenced by $\rho_{L W P S}$, which by definition indicates the average alteration that a particular scale experienced in the years spanning the entire selected period. On the other hand, the RVA analysis cannot separate alterations acting at different temporal scales, and analyzing the entire WPS may be cumbersome, although it includes all the relevant information needed to quantify the impacts.

[32] In order to facilitate detecting changes in streamflow characteristics, we devised a new methodology which integrates the wavelet transform with the RVA approach. The idea is simple: we apply the RVA methodology to the scaleaveraged wavelet power spectrum (SAWPS) $\bar{W}_{n}=\sqrt{\bar{W}_{n}^{2}}$, which by definition is a descriptor of the energy, i.e., the amplitude of the oscillations, contained within the targeted range of scales. In other words, the RVA approach is applied to the time series describing how strong is the variability at the selected scales.

[33] Figure 10 shows $\bar{W}_{n}$ for scales ranging from $s_{j 1}=256$ and $s_{j 2}=512$ days, which is a good descriptor of the strength of seasonal variations, and in particular of the difference between late spring maxima and winter minima. The time series can be broken down into three periods with decreasing 

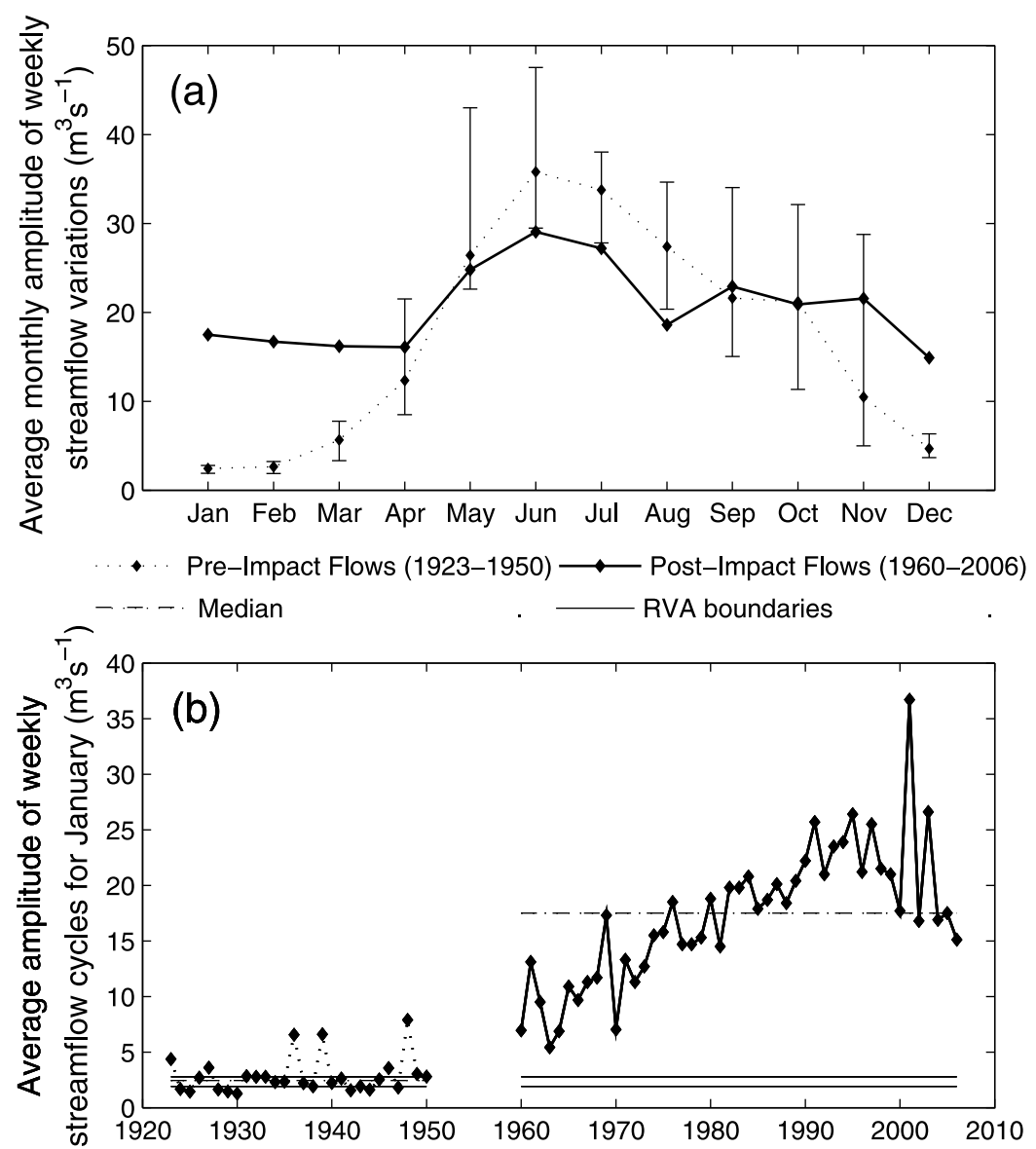

Figure 11. IHA analysis of the scale-averaged WPS for scales ranging from 4 to 8 days (weekly scale). (a) Monthly average amplitude of weekly SAWPS for the preimpact and the postimpact period. The vertical bars indicate the amplitude of the middle RVA class (i.e., between the 34th and the 67 th percentiles of the preimpact flows). (b) Time evolution of the average amplitude of weekly SAWPS for January.

energy. The preimpact period $(1923-1950)$ is characterized by stable oscillations with the highest median, followed by similar oscillations but with a lower median in the period 1960-1990. The median decreases further from 1990 to 2006, when $\bar{W}_{n}$ remains constantly below the minimum recorded during the preimpact period (see Figure 10). Furthermore, in the last 3 years the energy associated to the annual variability is the lowest of all the recorded period.

[34] The shift of the median in the early 1960s can be attributed to the regularization effect of reservoirs, which in order to meet the demand for energy were operated to accumulate part of the early summer runoff to use it in winter, thereby reducing the difference between summer high and winter low flows. However, the second sharp decrease of the median from $85 \mathrm{~m}^{3} / \mathrm{s}$ to $63.5 \mathrm{~m}^{3} / \mathrm{s}$, which corresponds to a $25 \%$ reduction, cannot be attributed to a change in the hydropower production. Rather, it should be attributed to the reduction of the average winter precipitation (i.e., the cumulative precipitation from December to February) of the period 1991-2006, which is 28\% lower than the average of the period 1960-1990, and thus compares well with the $25 \%$ reduction of the energy associated to the annual fluctuations. In addition, the cumulative precipitation from March to May are reduced by $11 \%$; their effect on early summer streamflows is complicated to quantify because of the difficulties in separating the solid precipitations and rainfall in spring. Note that 1960-1990 is the period used as reference in climatic studies to compute anomalies, and that the average winter precipitation of the period $1923-1950$ is $4.3 \%$ higher than the winter precipitation of this period.

[35] Figures 11a and $11 \mathrm{~b}$ summarize changes of the components of the signal associated to scales ranging from 4 to 8 days (weekly variations). Figure 11a shows that in the preimpact period the energy associated to these scales is low in winter, increases during springtime and peaks in June before decreasing again to the winter minimum, thus reflecting the stronger variability of streamflow produced in spring by snowmelt than in winter, when streamflow declines most of the time with small to negligible oscillations at the weekly scale. On the contrary, in the postimpact period the monthly average of the weekly $\bar{W}_{n}$ flattens because of the combined effect of larger $\bar{W}_{n}$ values from September to April, and slightly smaller values in the other months. The former effect is due to short-term operation of reservoirs, which store water during the weekends, when the cost of the energy is lower due to the reduced request, in order to increase hydropower production in the following days, when the price of energy, and thus the revenue, is higher. On the other hand, the attenuation of variability at 

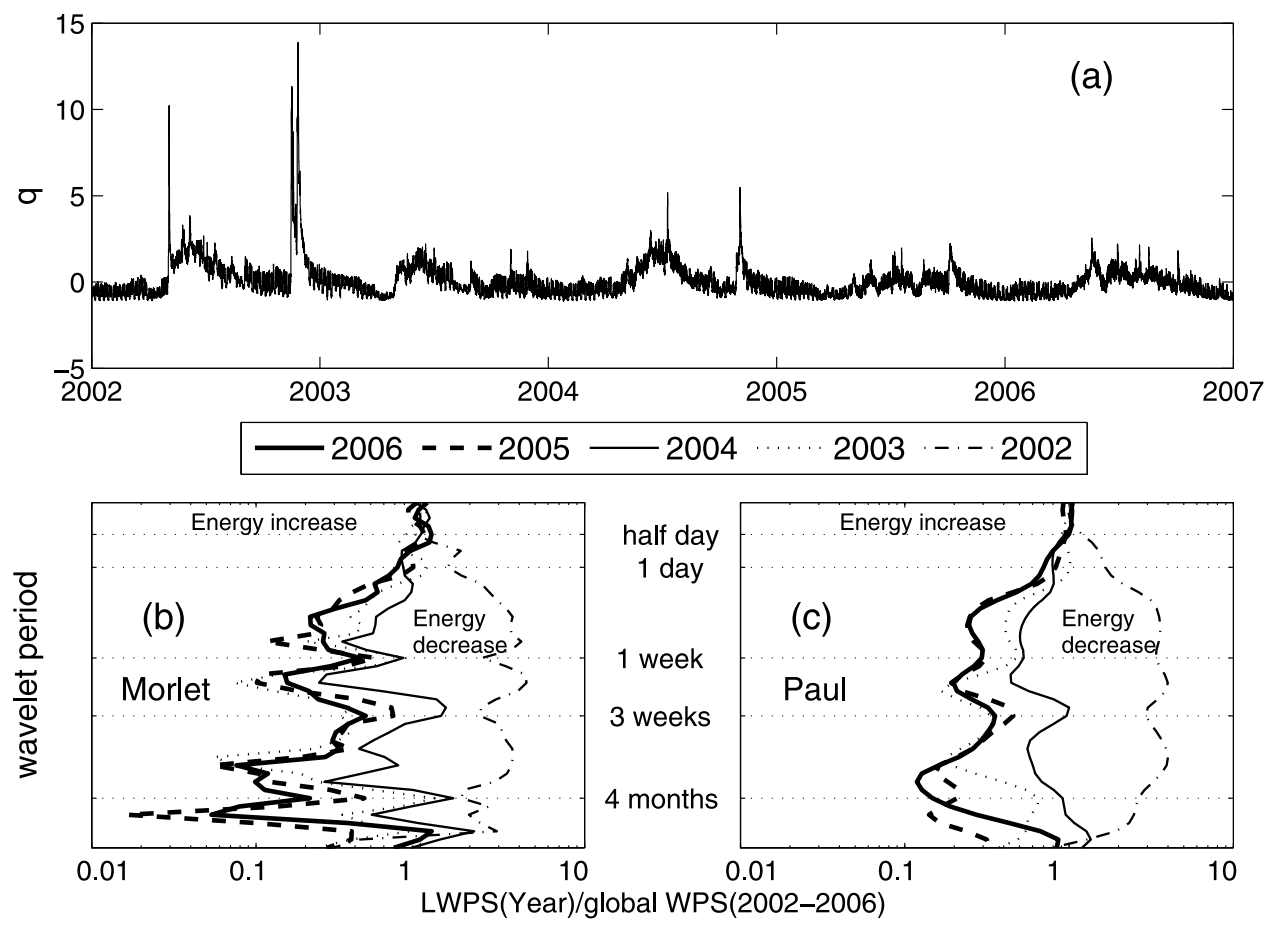

Figure 12. (a) Normalized streamflow $q\left(15^{\prime}\right.$ sampling interval) for the period 2002-2006. Yearly local wavelet power spectrum (LWPS) of the normalized streamflow, scaled with the global WPS of the whole period 2002-2006 obtained using (b) a Morlet and (c) a Paul $(m=6)$ wavelet basis.

the weekly scale from May to August may be explained with a reduced variability of the production due to a larger water availability. Furthermore, the monthly average of the weekly $\bar{W}_{n}$ falls outside the RVA targets (indicated in Figure 11a by vertical bars) from December to March, it remains just below the lower boundary of the interval from June to August and falls within the RVA targets in spring and fall.

[36] Furthermore, an accurate inspection of Figures 10 and 11a reveals that while in the preimpact period fluctuations were much larger at the annual scale than at the weekly scale (from about 10 times in winter to about two times in summer), in the postimpact period this difference is much smaller. Thus, similarly to annual variations, streamflow alterations at the weekly scale are well evidenced by the combined use of wavelets and RVA analyses.

[37] Figure 11b shows the time evolution of the average energy of weekly streamflow oscillation for January, which is one of the most impacted months at this scale, at least in the average (Figure 11a). The energy of the weekly oscillations, which is small and experiences small fluctuations in the preimpact period, shows a sharp increase in the years following 1960. This increasing trend continues until 2000, when early signs of a possible decline make their appearance, leading to values larger than the postimpact median (dashed horizontal line) over the period 1980-2000. This would imply that weekly streamflow cycles associated with hydropower production have been of increasing regularity from 1960 to 1980, have been very regular from 1980 to 2000 , and slightly decreased in regularity in the following years, with hydropower production occurring progressively more often also during the weekends.

\subsection{Wavelet Analysis of the High Sampling Frequency Data}

[38] The analysis of the daily time series showed that the energy associated to annual variability is attenuated in the postimpact period with the strongest attenuation between 2000 and 2006 when the climatic signature on these alterations is particularly evident. On the other hand the impact of hydropower production is evident on variability at the weekly scale, and possibly at smaller scales.

[39] In order to better analyze alterations at scales smaller than a few days, which are typically altered by hydropower production, we considered the WT of the time series of instantaneous streamflow sampled with $15^{\prime}$ time interval from 2002 to 2006 . We conducted the analysis by applying both the Morlet and Paul $(m=6)$ mother wavelets on the normalized time series shown in Figure 12a, which is obtained by removing the mean $\bar{Q}=143.7 \mathrm{~m}^{3} / \mathrm{s}$ from the original time series and then dividing by the standard deviation $\sigma_{Q}=102.8 \mathrm{~m}^{3} / \mathrm{s}$. Note that this time series cannot be analyzed by the RVA method which has been developed for daily data (and requires the comparison between preimpact and postimpact periods). One of the most important alterations occurring at time scales smaller than 1 day is the pulsating streamflow resulting from hydropower operations which concentrate the production at daylight when the price of the energy is the highest, whereas water is stored at night. This phenomenon is associated with hydropeaking, and results in sudden alterations of the streamflow with maximum to minimum water discharge ratios typically in the range $5 \div 10$, but higher values are also possible. The shift between minimum and maximum discharge usually occurs within a very short time span, typically between $15^{\prime}$ and $30^{\prime}$, 
depending on the characteristics of the turbine and alternator groups. The streamflow is therefore severely modified, since it assumes a pulsating behavior with high and low flows alternating at daylight and night, respectively. WT is the ideal tool in order to analyze such alteration.

[40] Figure 12b shows the local WPSs of the normalized streamflow computed separately for each year and normalized with the global WPS of the period 2000-2006, using the Morlet mother wavelet. The same quantity, obtained by adopting the Paul $(m=6)$ wavelet base is plotted in Figure $12 \mathrm{c}$ in order to show the sensitivity of the analysis to the choice of the mother wavelet.

[41] The two floods events that occurred in May and October 2002, respectively, have a strong influence on the local WPS which is much larger than in the other years at all scales except for those smaller than $12 \mathrm{~h}$. The other years show a consistent behavior: local WPS has a first peak at $12 \mathrm{~h}$ followed by a period of decreasing energy, which reaches a minimum at a scale of about 4 days and than increases to peak again at 1 week. However, differences are evident in the magnitude of the peaks. The magnitude of the peak at $12 \mathrm{~h}$ increases progressively from 2003 to 2006, while in the same time span the peak at the scale of 7 days reduces in magnitude.

[42] While the nearly threefold reduction from 2002 to 2003 is due to the absence of significant floods in 2003, the further reduction observable in the following years can be attributed to modifications of hydropower production, when a reduction of the number of weekends without production has been paralleled by a more regular subdaily trend. In other words, a more regular pulsating behavior results in a smaller difference between the days of the week, thereby reducing the strength of the weekly scale of variability and increasing the strength of the $12 \mathrm{~h}$ time scale, which corresponds to the typical duration of the pulse.

[43] Finally, inspection of Figures $12 \mathrm{~b}$ and $12 \mathrm{c}$ reveals that the results are independent of the choice of the mother wavelet, provided the wavelet base is chosen within the class of mother wavelets suitable to analyze oscillating signals.

\section{Conclusions}

[44] We explored the potential of integrating the range of variability approach with wavelet transform for assessing flow regime alterations in impacted rivers. This is motivated by the complementary nature of these two approaches. WT is the ideal tool to identify the main scales of variability and their variation in time, due to alterations of the flow regime. However, interpretation of the wavelet power spectrum may be difficult and in some aspects counterintuitive. On the other hand, RVA is intuitive but not suitable for separating the different causes of alteration and identifying the most impacted scales of variability. With this objective in mind, we first applied these two methodologies separately to daily streamflow data from 1923 to 2006 . Furthermore, in order to assess subdaily variability, we analyzed instantaneous streamflow data from 2002 to 2006 at $15^{\prime}$ sampling time step. This analysis cannot be performed with the RVA approach, which has been developed for daily data. Successively, we devised a new methodology based on the application of the RVA approach to the scale-averaged wavelet power spectrum, which describes how variations at selected scales change in time as a consequence of the alteration. The analysis of streamflow at the gauge station of Ponte San Lorenzo, showed that applying RVA to the time series constructed with the scale-averaged WPS over selected scales of variability, provides a better quantification of the alterations due to hydropower production and climate effects than the application of one of the two procedures. In particular, the combination of WT and RVA allowed to identify three periods with different dynamics of the annual scale of variability. The period from 1923 to 1950 is the one with the highest energy in the annual variations, it is followed by a period of relatively low energy from 1960 to 1990 , whereas the period from 1991 to 2006 is characterized by the lowest energy of the entire time series. The difference between the first and the last periods is remarkable and can be justified as the combined effect of impoundment of early summer flows in the reservoirs and the reduction of winter snowfall, which is the main cause of the strong reduction of the annual fluctuation from 1990 to 2006.

[45] While the effect of hydropower operations on streamflow cannot be separated from the effect of climate change at the annual scale of variability, the temporal dynamics introduced by changes in hydropower production are clearly evidenced at smaller scales. The analysis showed that, starting from 1960, the nature of low flows of the Adige River changed remarkably with an increase of base flow magnitude accompanied by a parallel increase in the frequency of low pulses, as well as a strong reduction of extreme low flows duration, with almost no variability within the year. These alterations can be linked to weekly streamflow oscillations due to hydropower production, which typically determine a marked increase in the absolute values of rise and fall rates of these events. The natural flow regime is less affected in the high-flow pulses as well as in the small and large floods.

[46] Wavelet transform applied to streamflow measurements with $15^{\prime}$ sampling interval from 2000 to 2006 showed a progressive strengthening of the $12 \mathrm{~h}$ scale of variability from 2003 to 2006 , which is probably due to the management of reservoirs which alternates storage of runoff at night to increase the production at daylight.

[47] The scale-targeted characterization of streamflow alteration presented in this work represents a first step in the definition of the environmental flow for impacted river systems like the Adige River. What the proposed methods can provide is a quantification of the time scales at which major hydrological alteration has occurred. To quantify the ecologically relevant time scales for a given ecological process would therefore require two major steps. The first is to precisely assess the hydrologically most impacted scales of alteration, which can be provided through the approach presented herein. A second analysis is then required to specifically quantify the ecological consequences that can be expected at the investigated range of scales. Although this second step goes beyond the scope of the present paper, two examples related to short and long time scales are briefly discussed below in order to exemplify our reasoning.

[48] Changes on short time scales (daily, weekly) cause the most immediate and negative impacts for the biotic components. Each hydropeaking wave affects the benthic organisms removing the fauna through drift [Boon, 1993; 
Troelstrup and Hergenrader, 1990; Cobb et al., 1992], may limit the use of the stream margins by fish and invertebrates which can be stranded [Perry and Perry, 1986] and the frequent changes in water level can reduce important riparian processes, such as denitrification and bioaccumulation. On longer time scales the set of patterns repeated in a yearly hydrograph are critical for regulating biotic production and diversity; the full spectrum of flow conditions represented by these types of flow events (low flows, extreme low flows, high-flow pulses, small floods, and large floods) are required in order to sustain riverine ecological integrity [Stanford et al., 1996; Poff et al., 1997; Baron et al., 2002] and to preserve near-natural sediment dynamics whose alteration can result in fine sediments clogging of the interstices and consequently in reduction of the hyporheic habitat available to invertebrates [e.g., Blaschke et al., 2003].

[49] The high degree of hydrologic alteration detected in the Adige River therefore suggests that several of the related ecosystem functions may be strongly reduced or even lost. However, in order to set environmental flow recommendations, a more specific knowledge of the expected ecological impacts needs to be investigated by detailed hydroecological analysis of the linkages between the observed hydrologic alteration and the biotic component at specific time scales. The present analysis provides several tools to quantify the degree of disturbance with respect to the natural variability. A possible indicator can be the range of scales in which the ratio $\rho_{L W P S}$ differs significantly from 1 (Figure 9). Minimizing the range of affected scales can be set as a target which defines the maximum alteration below which riverine ecosystem can maintain a good functionality.

[50] Acknowledgments. The authors would like to thank the staff at the Adige Water Authority for sharing data and information, in particular Renato Angheben, Manuel Montero Ramirez, and Donato Job. Streamflow data have also been provided by the Servizio Opere Idrauliche (SOI) of the Provincia Autonoma di Trento. A particular thank to the staff at the Department of Civil and Environmental Engineering, University of Trento (in particular Elena Possia) and Mauro Carolli (Edmund Mach Foundation) for helping to assemble the data sets and running some of the preliminary analysis. This research was cofunded by the Adige Water Authority, the Natural Science Museum of Trento, and the Department of Civil and Environmental Engineering of the University of Trento through the REPORT project. The second author acknowledges the support by the EU project AquaTerra (contract 505428 (GOCE)).

\section{References}

Allan, J. D., and A. S. Flecker (1993), Biodiversity conservation in running waters, BioScience, 43, 32-43.

Baron, N. L., J. S. Poff, C. N. Angermeier, P. L. Dahm, P. H. Gleick, N. G. Hairston, R. B. Jackson, C. A. Johnston, B. D. Richter, and A. D. Steinman (2002), Sustaining healthy freshwater systems, Issues Ecol., 10, 1-18.

Blaschke, A. P., K. H. Steiner, R. Schmalfuss, D. Gutknecht, and D. Sengschmitt (2003), Clogging processes in hyporheic interstices of an impounded river, the Danube at Vienna, Austria, Int. Rev. Hydrobiol., $88(3-4), 397-413$.

Boon, P. J. (1993), Distribution, abundance and development of trichoptera larvae in the River North Tyne following the commencement of hydroelectric power-generation, Regul. Rivers Res. Manage., 8(3), 211-224.

Botter, G., S. Zanardo, A. Porporato, I. Rodriguez-Iturbe, and A. Rinaldo (2008), Ecohydrological model of flow duration curves and annual minima, Water Resour. Res., 44, W08418, doi:10.1029/2008WR006814.

Bunn, S. E., and A. H. Arthington (2002), Basic principles and ecological consequences of altered flow regimes for aquatic biodiversity, Environm. Manage., 30(4), 492-507.

Cobb, D. G., T. D. Galloway, and J. F. Flannagan (1992), Effects of discharge and substrate stability on density and species composition of stream insects, Can. J. Fish. Aquat. Sci., 49(9), 1788-1795.
Cushman, R. M. (1985), Review of ecological effects of rapidly varying flows downstream from hydroelectric facilities, North Am. J. Fish. Manage., $5,330-339$.

Daubechies, I. (1992), Ten Lectures on Wavelets, Soc. for Ind. and Appl. Math, Philadelphia, Pa.

Enders, E. C., D. A. Scruton, and K. D. Clarke (2009), The natural flow paradigm and Atlantic salmon-Moving from concept to practice, River Res. Appl., 25(1), 2-15, doi:10.1002/rra.1227.

Foufoula-Georgiou, E., and P. Kumar (1995), Wavelets in Geophysics, Academic, San Diego, Calif.

Galat, D. L., and R. Lipkin (2004), Restoring ecological integrity of great rivers: Historical hydrographs aid in defining reference conditions for the Missouri River, Hydrobiologia, 422, 29-48, doi:10.1023/A:1017052319056.

Kaiser, G. (1994), A Friendly Guide to Wavelets, Birkhauser, Boston, Mass.

Karr, J. R., and E. W. Chu (1999), Restoring Life in Running WatersBetter Biological Monitoring, Island, Covelo, Calif.

Katul, G., and M. Parlange (1995), Analysis of land-surface heat fluxes using the orthonormal wavelet approach, Water Resour. Res., 31(11), $2743-2749$.

Katul, G., J. Schieldge, C. Hsieh, and B. Vidakovic (1998), Skin temperature perturbations induced by surface layer turbulence above a grass surface, Water Resour. Res., 34(5), 1265-1274.

Kumar, P., and E. Foufoula-Georgiou (1993), A multicomponent decomposition of spatial rainfall fields: 1. Segregation of large-scale and smallscale features using wavelet transforms, Water Resour. Res., 29(8), $2515-2532$.

Kwon, H.-H., U. Lall, and A. F. Khalil (2007), Stochastic simulation model for nonstationary time series using an autoregressive wavelet decomposition: Applications to rainfall and temperature, Water Resour. Res., 43, W05407, doi:10.1029/2006WR005258.

Lashermes, B., and E. Foufoula-Georgiou (2007), Area and width functions of river networks: New results on multifractal properties, Water Resour. Res., 43, W09405, doi:10.1029/2006WR005329.

Lau, K. M., and H. Weng (1995), Climate signal detection using wavelet transform: How to make a time series sing, Bull. Am. Meteorol. Soc., 76(12), 2391-2402.

Maiolini, B., and M. C. Bruno (2008), The river continuum concept revisited: Lessons from the Alps, in The Water Balance of the Alps, Alp. Space Man Environ., vol. 3, pp. 67-76, Innsbruck Univ. Press, Innsbruck, Austria.

Mathews, R., and B. D. Richter (2007), Application of the indicators of hydrologic alteration software in environmental flow setting, J. Am. Water Resour. Assoc., 43(6), 1400-1413.

McCully, P. (1996), Silenced Rivers. The Ecology and Politics of Large Dams, Zed, London.

Morlet, J. (1983), Sampling theory and wave propagation, in Issues in Acoustic Signal/image Processing and Recognition, NATO ASI Ser., Ser. $F$, vol. 1, edited by C. H. Chen, pp. 233-261, Springer, New York.

Nakken, M. (1999), Wavelet analysis of rainfall-runoff variability isolating climatic from anthropogenic patterns, Environ. Modell. Software, 14, 283-295, doi:10.1016/S1364-8152(98)00080-2.

Nilsson, C., C. A. Reidy, M. Dynesius, and C. Revenga (2005), Fragmentation and flow regulation of the world's large river systems, Science, 308(5720), 405-408, doi:10.1126/science.1107887.

Perry, S. A., and W. B. Perry (1986), Effects of experimental flow regulation on invertebrate drift and stranding in the Flathead and Kootenai rivers, Montana, USA, Hydrobiologia, 134, 171-182.

Poff, N. L., J. D. Allan, M. B. Bain, J. R. Karr, K. L. Prestegaard, B. D. Richter, R. E. Sparks, and J. C. Stromberg (1997), The natural flow regime, BioScience, 47, 769-784.

Pringle, C. M., M. C. Freeman, and B. J. Freeman (2000), Regional effects of hydrologic alterations on riverine macrobiota in the new world: Tropical-temperate comparisons, BioScience, 50, 807-823.

Qi, X., and R. M. Neupauer (2008), Wavelet analysis of dominant scales of heterogeneous porous media, Water Resour. Res., 44, W09406, doi:10.1029/2006WR005720.

Revenga, C., N. Brunner, K. Kassem, and R. Payne (1999), Pilot Analysis of Global Ecosystems: Freshwater Ecosystems, World Resour. Inst., Washington, D. C.

Richter, B., and G. A. Thomas (2007), Restoring environmental flows by modifying dam operations, Ecol. Soc., 12(1), article 12, http://www. ecologyandsociety.org/vol12/iss1/art12/.

Richter, B., J. Baumgartner, J. Powell, and D. Braun (1996), A method for assessing hydrologic alteration within ecosystems, Conserv. Biol., 10, 1163-1174, doi:10.1046/j.1523-1739.1996.10041163.x.

Richter, B., J. Baumgartner, W. Robert, and D. Braun (1997), How much water does a river need?, Freshwater Biol., 37(1), 231-249, doi:10.1046/ j.1365-2427.1997.00153.x. 
Richter, B., J. Baumgartner, R. Wigington, D. Braun, and J. Powell (1998), A spatial assessment of hydrologic alteration within a river network, Regul. Riv., 14(4), 329-340, doi:10.1002/(SICI)1099-1646(199807/08)14:4< 329:AID-RRR505>3.0.CO;2-E.

Saco, P., and P. Kumar (2000), Coherent modes in multiscale variability of streamflow over the United States, Water Resour. Res., 36(4), $1049-1067$.

Scott, M. L., G. T. Auble, and J. M. Friedman (1997), Flood dependency of cottonwood establishment along the Missouri River, Montana, USA, Ecol. Appl., 7(2), 677-690.

Stanford, J. A., J. V. Ward, W. J. Liss, C. A. Frissell, R. N. Williams, J. A. Lichatowich, and C. C. Coutant (1996), A general protocol for restoration of regulated rivers, Regul. Rivers Res. Manage., 12(4-5), 391-413.

Steel, E. A., and A. Lange (2007), Using wavelet analysis to detect changes in water temperature regimes at multiple scales: Effects of multipurpose dams in the Willamette river basin, River Res. Appl., 23, 351-359, doi:10.1002/rra.985.

Toner, M., and P. Keddy (1997), River hydrology and riparian wetlands: A predictive model for ecological assembly, Ecol. Appl., 7(1), 236-246, doi:10.1890/1051-0761(1997)007[0236:RHARWA]2.0.CO;2.
Torrence, C., and G. P. Compo (1998), A practical guide to wavelet analysis, Bull. Am. Meteorol. Soc., 79, 61-78.

Troelstrup, N. H., and G. L. Hergenrader (1990), Effect of hydropower peaking flow fluctuations on community structure and feeding guilds of invertebrates colonizing artificial substrates in a large impounded river, Hydrobiologia, 199(3), 217-228.

Ward, J. V. (1989), The four-dimensional nature of lotic ecosystems, J. North Am. Benthol. Soc, 8(1), 2-8.

Ward, J. V., K. Tockner, U. Uehlinger, and F. Malard (2001), Understanding natural patterns and processes in river corridors as the basis for effective river restoration, Regul. Rivers, 17(4-5), 311-323.

A. Bellin, A. Siviglia, and G. Zolezzi, Department of Civil and Environmental Engineering, University of Trento, via Mesiano 77, Trento, I-38100, Italy. (alberto.bellin@ing.unitn.it; nunzio.siviglia@ing.unitn.it; guido.zolezzi@ing.unitn.it)

M. C. Bruno and B. Maiolini, Research Innovation Center, IASMA, Edmund Mach Foundation, Via E. Mach 1, San Michele all'Adige, I-38010, Italy. (cristina.bruno@iasma.it; bruno.maiolini@iasma.it) 